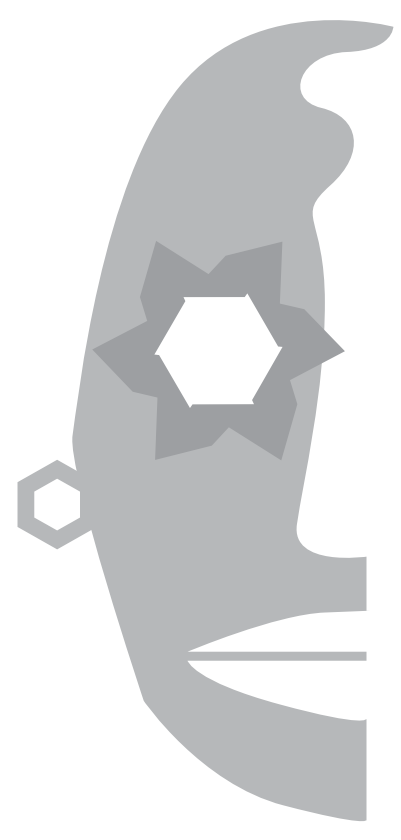

\title{
La unificación del lenguaje como dispositivo de resistencia en La guaracha del Macho Camacho (1976), de Luis Rafael Sánchez
}

Juan Camilo

Galeano Sánchez

University of Cincinnati

\section{Resumen}

El presente artículo estudia la manera como se transgreden cánones lingüísticos, gramáticos y literarios en La guaracha del Macho Camacho (1976), novela del puertorriqueño Luis Rafael Sánchez. Tiene por objetivo general demostrar que el lenguaje es un mecanismo de resistencia frente a los grupos hegemónicos, por el cuestionamiento de su posición en la sociedad puertorriqueña. Para lograr tal propósito se plantean tres objetivos secundarios: primero, identificar la contradicción, en el contexto puertorriqueño, entre los valores sociales propuestos por Estados Unidos y aquellos que se gestan en la isla; segundo, explicar su carácter de novela "anti-nacional", en la medida en que no reproduce un lenguaje único sino que refleja la diglosia propia del hablante callejero y, tercero, advertir la incidencia del concepto de hibridación, según Bajtín, como mecanismo de construcción de un registro lingüístico distinto al de las partes que lo componen. Se concluye, de ese modo, que el texto de Sánchez critica a la clase dominante de la sociedad puertorriqueña envileciéndola, haciéndola tan vulgar como aquellos que se encuentran en sus antípodas, con quienes no tienen diferencias -al menos en el texto- demasiado notables.

Palabras clave: Luis Rafael Sánchez; La guaracha del Macho Camacho; hibridación; resistencia social; diglosia. 


\begin{abstract}
This article discusses how literary, linguistic, and grammatical canons are violated in La Guaracha del Macho Camacho. Its overall objective is to show that language has been used as a mechanism of resistance against hegemonic groups as it questions their position in Puerto Rican society. To achieve this objective, we propose three secondary objectives: first, identify the contradiction in the context of Puerto Rico between the social values proposed by the United States and those held on the island; second, explain the "anti-national" nature of the novel to the extent that it does not portray a single language but rather reflects the diglossia of street language; and, third, illustrate the use of Bakhtin's concept of hybridization as a mechanism of construction of a linguistic register that is different from its component parts. The article concludes that Sanchez's text criticizes the ruling class of Puerto Rican society by vulgarizing it and making it as common as the lower classes, with whom they have no noticeable differences (at least in this text).
\end{abstract}

Keywords: Luis Rafael Sanchez; La guaracha del Macho Camacho; hybridization; social resistance; diglosia.

No hemos de saber inglés los puertorriqueños para suicidarnos culturalmente disolviéndonos en el seno turbulento de la Unión norteamericana - "el norte revuelto y brutal que nos desprecia”, que decía Martí-, sino para integrarnos con mayor facilidad y ganancia en el rico mundo caribeño al que por imperativo histórico pertenecemos José Luis González (1980)

Desde su propio título, La guaracha del Macho Camacho, el texto de Luis Rafael Sánchez está invitando a quien se aventure dentro de sus páginas, a echar un vistazo a una de las manifestaciones más palpables de subalternidad en el contexto hispanohablante: la diferencia de clases sociales en la América insular, más específicamente en Puerto Rico. La guaracha, ritmo de origen cubano pero popular en todo el Caribe, no es precisamente el tipo de música que escucharían las 'comunidades letradas', las familias tradicionales o los profesionales pudientes; por el contrario, sus letras picantes, bufas, satíricas, se instalaron en los sectores más relegados de la sociedad, convirtiéndose en su mecanismo de expresión por excelencia (al menos antes de que estos fueran invadidos por el arribismo del reggaetón). En consonancia con esto, el texto de Sánchez pretende mostrar, desde su inicio, la forma como interactúan personas a un lado y otro de la escala social en la Isla, haciendo una muy interesante propuesta escritural que dialoga con el poder discursivo de Guillermo Cabrera Infante, la estética de Severo Sarduy y la literaturización de lo kitsch de Manuel Puig. En este orden de ideas, podría pensarse que, merced a tan señeras influencias el texto fue aplaudido desde su publicación; sin embargo, la crítica local fue sumamente dura con La guaracha del Macho Camacho en cuanto esta vio la luz, en razón de su sátira feroz hacia las clases dominantes de Puerto Rico. 
Los estudios literarios no han escatimado esfuerzos para analizar la propuesta textual de Sánchez, centrándose estos, muy particularmente, en aspectos como la estructura paródica, la deconstrucción de los personajes (dándoles, en apariencia, dos vidas paralelas a cada uno de ellos) y la manipulación del tiempo, entre otros. El trabajo que aquí se presenta, aun contextualizado dentro de la literatura, dirige su mirada a la manera como se expresa el texto y a su transgresión de cánones lingüísticos, gramáticales y literarios. Así las cosas, tiene por objetivo general demostrar que el lenguaje en La guaracha del Macho Camacho funciona como un mecanismo de resistencia frente a los grupos hegemónicos, por el cuestionamiento a su posición en la sociedad puertorriqueña. Para lograr tal propósito se plantean tres objetivos secundarios: primero, identificar las contradicciones, en el contexto puertorriqueño, entre los valores sociales propuestos por su metrópoli, Estados Unidos, y aquellos que se gestan en el seno de la isla; segundo, explicar el carácter de novela "anti-nacional" de La guaracha del Macho Camacho, en la medida en que no reproduce un lenguaje único, generalmente aceptado, sino que refleja la diglosia propia del hablante callejero; y tercero, advertir la incidencia del concepto de hibridación, según M. Bajtín, como mecanismo de construcción de un registro lingüístico distinto al de las partes que lo componen. Se concluirá, de este modo, que el texto de Sánchez critica a los grupos hegemónicos de la sociedad puertorriqueña envileciéndolos, haciéndolos tan vulgares como aquellos otros grupos que se encuentran en sus antípodas, con quienes no tienen diferencias -al menos en el texto-demasiado notables.

Antes de hacer una aproximación crítica a la novela, es importante acercarse a su propuesta narrativa. La novela relata la historia de cinco personajes vinculados por un embotellamiento ("tapón") vehicular, un miércoles a las cinco de la tarde, en una calle de San Juan. Entre estos personajes se encuentra el senador Vicente Reinosa, político de derecha, pro-estadounidense y padre de familia quien es, al mismo tiempo, El Viejo, millonario, putañero y con un gusto especial por las carnes prietas. Alrededor de Reinosa se encuentran su esposa, Graciela Alcántara y López de Montefrío, católica, aristócrata, frígida y adicta al psicoanálisis; su hijo Benny, un adolescente que se masturba pensando en el Ferrari que su padre le acaba de regalar (alegría ensombrecida porque en Puerto Rico no existe una autopista en la cual pueda correrlo a toda velocidad); y su amante La Madre, también nombrada en la novela como La China Hereje, una mujer de clase baja obsesionada con el dinero que le puede sacar al senador y que sueña con ser la próxima Iris Chacón. El cuadro se completa con Doña Chon, una anciana supersticiosa y tradicionalista, vecina de La Madre y niñera de su hijo El Nene, un niño con retardo mental y deformidades físicas. Antes de que la novela termine Benny habrá matado a El Nene con su Ferrari. La sugerencia de Sánchez es que la vida de nadie, ni siquiera la de La Madre, cambiará radicalmente por ello. 
De entrada, es importante reconocer que no es gratuito el hecho de que la caracterización de los personajes se encuentre tan cargada ideológicamente: todos los que participan de esta 'guaracha' se encuentran vinculados por características más o menos arquetípicas dentro de las representaciones sociales puertorriqueñas vigentes al momento de la escritura de la novela: el aristócrata que busca amantes en los barrios bajos, el niño pijo sin más ideas que manejar su coche, la advenediza que cree que su única alternativa para salir de pobre es convertirse en vedette de televisión. La propuesta autoral, con su cáustico sentido del humor, busca comunicar los aspectos más desagradables de una sociedad que arrastra como un lastre todas las herencias de sus etapas coloniales. En efecto, el Puerto Rico del que habla Sánchez refleja sus condiciones sucesivas de puerto negrero, colonia española y (neo)colonia estadounidense: racista, clasista y oprimida en su oneroso confort de "estado libre-asociado" de los Estados Unidos, la Isla resulta, al menos en el terreno sociocultural, "demasiado americana para los latinos, demasiado latina para los americanos".

Es este el contexto sociocultural que acrisola la voz narradora de La guaracha del Macho Camacho, el del Puerto Rico situado a medio camino entre la latinidad y la (norte)americanidad, cuyo español es alterado por el inglés y cuyo inglés se asume como imposición, pero se adopta como un símbolo de estatus social; este Puerto Rico que se aferra a su herencia hispana y la reclama vigorosamente, mientras su población emigra masivamente a Nueva York y sus descendientes terminan olvidando que su lengua materna es el español. Sobre esta voz afirma Cruz: "[...] La guaracha is read not as an up-beat novel, a carnavalesque celebration of humor, but as a searing indictment of Puerto Rico's colonial reality and the role of the American-controlled mass media in maintaining this colonial status." (Cruz,1985: 36) El ejercicio de dominación estadounidense, como puede verse, se encuentra más allá de lo económico: las representaciones sociales puertorriqueñas se "norteamericanizan" en la medida en que los medios masivos de comunicación están permeados por la cultura de la metrópoli, haciendo que valores tradicionales de la isla se reconfiguren para articularse a aquellos que los dominantes consideran deseables. Al respecto, indica J. L. González:

[...] el desmantelamiento progresivo de la cultura de la élite puertorriqueña bajo el impacto de las transformaciones operadas en la sociedad nacional por el régimen colonial norteamericano ha tenido como consecuencia, más que la 'norteamericanización' de esa sociedad, un trastocamientointerno de valores culturales. El vacío creado por el desmantelamiento de la cultura de los puertorriqueños 'de arriba' no ha sido, ni mucho menos, por la intrusión de la cultura norteamericana, sino por el ascenso cada vez más palpable de la cultura de los puertorriqueños 'de abajo'. (González,1980: 29) 
Es paradójico, no obstante, que los valores de las clases populares descuellen merced a la intervención de quienes simpatizan con las élites: el prolongado dominio de los Estados Unidos sobre Puerto Rico se erige sobre las buenas relaciones de las clases dirigentes de la isla, que históricamente han auspiciado la "libre asociación" con el gobierno metropolitano. Esta paradoja es señalada por el mismo González: "[...] así como sus valores culturales le sirvieron a la clase propietaria para resistir la 'norteamericanización', esa misma 'norteamericanización' le ha servido a la masa popular para impugnar y desplazar los valores culturales de la clase propietaria" (González, 1980: 34). Una doble paradoja podría entreverse considerando que la clase alta puertorriqueña se enorgullece de su pasado hispano y se vanagloria de su correcto uso de la lengua castellana, mientras ignora la penetración de la cultura estadounidense a su territorio y la consecuente mezcla de lenguas provocada por esta.

Teniendo lo anterior como base, podría pensarse que La guaracha del Macho Camacho juega, especularmente, con una lengua cuya 'puridad' se encuentra en entredicho, o lo que es más, en un verdadero proceso de deconstrucción: “[...] un lenguaje castellano salpicado de inglés que contiene una mezcla de ambos idiomas con matices españoles [...] para representar la invasión cultural y política de España primero y luego de Estados Unidos en Puerto Rico" (Policarpo, 2011: 91). A esta apreciación podrían agregarse tres factores más: primero, el uso del pastiche (los pasajes narrativos descontextualizados, los versos improcedentes, la mención al desgaire de ciertos autores) como herramienta para marcar distancia con la tradición literaria hispanoamericana en la que, teóricamente, la literatura puertorriqueña se encuentra inscrita; segundo, la constante remisión a la cultura de masas que, aun en su condición de artefacto comercial, es tratada con el mismo celo que las fuentes eruditas más autorizadas y, tercero, la "cristalización", como la denomina Rotker (1991: 29), del registro hablado como leguaje autónomo mediante la inclusión de "[...] coloquial Puerto [...] politicalspeech, neologisms, rhymes, metalinguistics, argot and aphorisms like the one which unifies the novel: 'la vida es una cosa fenomenal'" (Ben-Ur, 1977: 1035).

Benny destacaba los libros en la trinchera del sobaco y confiaba en que el conocimiento le llegara por el fenómeno de ósmosis: iqué mamey! Ejemplo: Benny, asustado porque mañana por la mañana tomará un examen final, se deposita esta noche en la Sala de Resúmenes de la Biblioteca General de la Universidad de Puerto Rico: o sea que si Don Quijote de la Mancha viene en tamaño familiar de veinte páginas yo no voy a gastar la vida leyendo el de verdad: o sea que yo aprendí de niño que los libros se quedan y uno se va, o sea que yo no soy un estofón, o sea que yo soy un tipo listo, o sea que en sexto grado me decían Benny Listerine. Benny volvía a la casa con los bolsillos llenos de des y efes: Mami de Benny decía: antes con un donativo para restaurar el altar tal de la Purísima 
o La Altagracia se arreglaba el majadero asunto de las notas: por eso yo estoy de acuerdo con una elegante Asociación de Padres y Maestros de Niños Universitarios. Papito Papitín decía: celebrar en fecha a convenir un gettogether de maestros en el molto bello jardino de tu Mamá: gettogether con mozos uniformados, coldcuts de La Rotisserie, toneles de Beaujolais y Lambrusco espumoso: gettogether que cargo a mis gastos de representación senatorial. (Sánchez, 1976: 129). (Las cursivas son mías)

La anterior cita, aunque extensa, resulta representativa de los elementos antedichos: en primer lugar, ese español escrito que no solamente desconoce las más elementales normas de puntuación sino que, además, al tratar de imitar el lenguaje común de los personajes, lo atiborra de extranjerismos para dejar en claro cuán esnobistas son los hablantes. Luego, la mención a Don Quijote: la obra de Cervantes, lejos de ser ese hito de la cultura hispana al que todo el continente rinde reverencia, en la novela se convierte en una frivolidad fácilmente intercambiable por una versión resumida, especial para estudiantes vagos. La mención de marcas comerciales y denominaciones de origen de comidas y bebidas muestra una deliberada intención del autor por mostrar cómo la cultura de masas y la mercadotecnia acaban por saturar las conversaciones usuales de las familias puertorriqueñas. Por último, el uso de expresiones coloquiales como "mamey" y "estofón", que bien podrían ser usados del lado opuesto al que se encuentra Benny en la escala social, da cuenta de que el lenguaje hablado tiene la virtualidad de cerrar brechas entre las clases, sin que necesariamente el clasismo deje de existir.

Estos elementos, sin embargo, no arrojarían por sí solos un panorama certero sobre la posición de la novela dentro de la literatura puertorriqueña. Es claro que La guaracha del Macho Camacho hace una sinécdoque de la Isla a partir de sus personajes, muestra representativa de quiene habitan en ella, vinculados como oyentes (ora entusiastas, ora apáticos) de la canción "La vida es una cosa fenomenal" y que, a su ritmo, viven toda clase de peripecias, como ocurriría en cualquier guaracha. Teniendo en cuenta que el autor pretende representar lo que considera como una 'realidad' de la Isla, al menos desde una perspectiva alegórica, no podría descartarse cierta atracción suya por el concepto de "novela nacional' y hacer de este texto su apuesta para vincularse a esta tradición literaria. Mas no es necesario un estudio comparativo de los paradigmas del género anotado (las novelas románticas decimonónicas y los denominados libros monstruosos, combinaciones de ensayo, poesía y narrativa que las sucedieron) para determinar que la novela de Sánchez no tiene este carácter. Baste considerar que no hay una narración estrictamente lineal, no se analizan los elementos constitutivos del "ser nacional puertorriqueño" y no se le apunta al relato un proyecto fundacional de nación. De este modo, es viable admitir que: 
[La guaracha...] no es [...] una novela de identidad nacional al estilo de la gauchesca, por ejemplo, donde se erigen tipos y hablas casi con la misma pretensión de verdad que la de un documento testimonial. En el caso de La guaracha... estos tipos y hablas - tan institucionalizados ya en la literatura puertorriqueña previa- son sometidos a procedimientos paródicos. (Rotker, 1991: 29)

Súmese a esto que en la novela nacional (especialmente en la argentina), la ciudad se representa como entidad civilizadora, mientras que en La guaracha del Macho Camacho esta se incorpora como una entidad más allá de lo barbárico, bestial. Esta postura se refuerza en la diglosia de la que se ha hablado antes: el paso inadvertido entre el inglés y el español, tal como lo presenta Sánchez, es una práctica incivilizada, baja, totalmente opuesta a la lengua noble que debe reconocer el lector de novelas nacionales. Un ejemplo claro de esta postura se encuentra en la observación de Policarpo: “[...] Sánchez usa las preposiciones en español al final de frases, a la manera incorrecta y acostumbrada del inglés estadounidense. Igualmente lo hace para resaltar el tipo de colonialismo cultural de intromisión en la lengua, con el mismo tipo de corrupción lingüística [...]" (Policarpo, 2011: 92). La comunicación a través de una lengua entreverada con otra desnaturaliza el ideal de nación unificada y hace que el texto pueda considerarse, en el mejor de los casos, como una novela "anti-nacional": aquella que, más que generar sentido de pertenencia a un territorio o a un pueblo determinado, muestra las fisuras sociales que impiden la generación de ese sentimiento, siendo la lengua, para el caso de Puerto Rico, la mayor de ellas, aunque no la única.

No quiere esto decir que La guaracha del Macho Camacho distorsione la percepción de Puerto Rico; por el contrario, viene a ser un instrumento más que idóneo para acercarse, tanto literaria como sociológicamente, a la vida en la Isla. No en vano el autor se esmera en presentar sus personajes de la manera más verosímil posible y su recurso, por antonomasia, es la reproducción del lenguaje callejero, a la manera que se ha analizado con antelación. Del mismo modo, no puede ignorarse el hecho de que, por más 'experimental' que sea su propuesta estructural, no deja de ser un texto depositario de una ideología muy en boga entre los intelectuales puertorriqueños durante los años setenta. Por otro lado, a pesar de que exista una indiscutible sobreestetización de ciertos aspectos del lenguaje (hablar del "fresco acto copulativo", baste como ejemplo), de ninguna manera llegan estos a obstaculizar la recepción del texto. Es imposible no coincidir con Alonso en el sentido de que:

The novel attempts the portrayal of Puerto Rican society in its entirety, mirroring the way in which "La guaracha del Macho Camacho" has invaded all strata of the social order, leaving no one unperturbed in its wake. The rich, pro-American senator; his frigid and neurotic wife; his black, lower class mistress- all are denuded by the pro bing narrator and all are seduced as well, willingly or not, by the pulsating lyrics of "La guaracha del Macho Camacho. (Alonso,1985: 354) 
Esta reflexión puede llevarse más allá: a pesar de las diferencias que existan entre ellos, ricos y pobres, intelectuales e iletrados, políticos y apolíticos, son retratados por Sánchez como elementos de una misma colectividad marcada, no solo por la dominación territorial-cultural-social de Estados Unidos, sino por su desatención a elementales valores humanos como la honestidad, la solidaridad o el amor. En términos muy básicos, el denominador común del pueblo puertorriqueño retratado por el autor es su inmoralidad: la duplicidad del senador, la superficialidad de su hijo, el clasismo de su esposa, el arribismo y la indolencia de su amante o la pacatería de la niñera. Así las cosas, la idea de 'nación puertorriqueña' que se busca transmitir en el texto se encuentra en la intersección de dos circunstancias igualmente aciagas para la Isla: por un lado, la de colonia supérstite o neocolonia; por otro, la de unos habitantes que no son capaces de pensarse a sí mismos más allá de sus propias ambiciones.

La intención autoral de Sánchez, así vista, se encuentra en impugnar la escala de valores vigente en el Puerto Rico de su tiempo, a la par que desmontar tópicos como la 'civilización' de los ricos y la 'inocencia' de los pobres. En este sentido, el autor no se identifica como agente de los intereses de ninguna clase social, tampoco parece querer definir la "puertorriqueñidad" desde su texto de ficción o, más aún, hacer predicciones sobre el Puerto Rico del mañana, esa isla que vencerá los problemas de clase para erigirse como nación caribeña. No, el acto de resistencia en La guaracha del Macho Camacho es mostrar que las clases sociales, por más lejos que estén, terminan igualándose por lo bajo.

Es aquí, precisamente, donde el lenguaje acorta distancias entre las clases sociales, merced al uso que, de extremo a extremo, se hace de él. La incidencia del concepto bajtiniano de "hibridación" es meridianamente clara en el texto, en el entendido de que esta comporta "[...] una mezcla de dos lenguajes sociales dentro de los límites de una sola palabra, un encuentro, dentro de la arena de un enunciado, entre dos conciencias lingüísticas diferentes [...]" (Bajtín, 1981: 358. Mi traducción). Sánchez no tiene mayor interés en corregir, así sea literariamente, el habla puertorriqueña de sus personajes; de hecho, como autor, se regodea en ese estado de deconstrucción en el que esta se encuentra y, aun cuando la mímesis de esa representación pueda ser cuestionable, lo que le interesa es establecer un sustrato común de las fórmulas que los personajes podrían usar para dialogar en la vida real. De esa manera, la diglosia narrada deviene un lenguaje estándar, sin una estructura gramatical definible, en el que los referentes culturales se convierten en idiolecto y el ritmo del habla en registro discursivo. Tómense como ejemplos las dos siguientes citas del texto:

Y las dos veces que me he perdido el show de Iris Chacón en la televisión me han comentado que Iris Chacón ha mapeado, ha barrido, ha acabado. Y las dos 
veces que me he perdido el show de Iris Chacón en la televisión me han comentado que le pusieron la cámara en la barriga y esa mujer parece que se iba a romper de tanto que se meneaba, como si fuera una batidora eléctrica, como si fuera una batidora eléctrica con un ataque de nervios. (Sánchez, 1976:18)

O sea Papi, éntrale a una carretera del cará. O sea Papi, endereza las carreteras de este país torcido, O sea Papi, que ese proyecto salga de tu azotea pensante, de tu cráneo engrasado. O sea Papi, que si tú haces una pista bien hecha donde la juventud pueda envenenar sus paletas con un millaje tipo MarysolMalaret: puertorriqueña Miss Universo y gloria nacional por decreto. O sea Papi, que la juventud te estaremos agradada. (Sánchez, 1976: 76)

En la primera cita está hablando La Madre, en la segunda Benny. Nótese cómo cada uno, a su manera, expresa sus sueños más acariciados: ella quiere ser Iris Chacón; él, una autovía para correr en su Ferrari a toda velocidad. Las diferencias ideológicas subyacentes a cada uno de los textos guardan cierta distancia -aun cuando es clara la trivialidad que en ambos casos se quiere enunciar-, pero las formas usadas por ambos para comunicar esos sueños tienen indiscutibles puntos de contacto: la reiteración casi obsesiva del referente (Iris Chacón, la carretera), las rebuscadas metáforas, la españolización forzada de términos del habla inglesa ("mapeado" como verbo para designar la acción de usar una mop - fregona, trapeador-; "agradada" en lugar de decir "agradecida", más cercano al grateful que el personaje quiere expresar), el uso de figuras mediáticas para reforzar la potencia comunicativa de la expresión y, finalmente, la manera como la lengua hablada trasciende los límites de lo estrictamente narrativo para manifestar, como marca textual peculiar, que el personaje que está hablando es puertorriqueño.

En conclusión, La guaracha del Macho Camacho se presenta como un mecanismo de resistencia frente a la discriminación en Puerto Rico, en tanto iguala a las clases altas con las bajas, para lo que se vale de dos estrategias narrativas: la primera, presentar a todos los personajes en el mayor esplendor de sus miserias, buscando mostrar que ricos y pobres son igualmente ruines, a pesar de que carguen con distintos lastres. La segunda, crear un lenguaje fijo, juguetón, que conecte sus diversas formas de hablar en un único registro lleno de expresiones de la lengua inglesa, remisiones a la cultura pop y pequeñas infidelidades a las letras hispanoamericanas.

El autor logra, así, un ataque más efectivo a la discriminación basada en la división en clases sociales, debido a que trasciende el manido "nosotros-ellos" y los consecuentes memoriales de agravios inherentes a él, para construir un gran "nosotros" del que nadie se puede apartar. No es necesario, en este orden de ideas, hacer una separación del lenguaje que se usa de un lado y otro de la escala social pues, conlleve o no el uso del inglés, acuse o no una actitud 
colonialista, lo cierto es que ni la clase alta se encuentra tan ennoblecida ni la clase baja está tan abatida. La guaracha del Macho Camacho se convierte, entonces, en una verdadera guaracha: puede gustar, puede disgustar, pero a nadie le permite quedar indiferente.

\section{Referencias}

Alonso, C. J. (1985). "La guaracha del Macho Camacho: The Novel as Dirge". $M L N, 100,2$, pp 348-360.

Ben-Ur, L. E. (1977). Book Review: "La guaracha del macho Camacho". Hispania, 60, 4, pp 1035-1036.

Cruz, A. (1985). "Repetition and the Language of the Mass Media in Luis Rafael Sanchez's "La guaracha del Macho Camacho". Latin American Literary Review, 13, 26, pp 35-48.

González, J. L. (1980). El país de cuatro pisos y otros ensayos. Río Piedras, Puerto Rico: Ediciones Huracán.

Bakhtin, M. M., \& Holquist, M. (1981). Thedialogicimagination: Fouressays. Austin: University of Texas Press.

Alcibiades, P. (2011). "Conciencia y subversión en: La Guaracha del Macho Camacho. Entre tapones y guarachas con Luis Rafael Sánchez". Journal of intercultural disciplines, Winter, pp 91-99.

Rotker, S. (1991). "Claves paródicas de una literatura nacional: La guaracha del Macho Camacho”. Hispamérica, Diciembre 01, 20, 60, pp 23-31.

Sánchez, L. R. (1976). La guaracha del macho Camacho. Buenos Aires: Ediciones de la Flor. 